\section{(6) OPEN ACCESS}

\title{
Could kinesiology taping help mitigate pain, breathlessness and abdominal-related symptoms in cancer?
}

\author{
Gourav Banerjee, ${ }^{1}$ Alison Rose, ${ }^{2}$ Michelle Briggs, ${ }^{3,4}$ Mark I Johnson ${ }^{5}$
}

${ }^{1}$ Centre for Pain Research, School of Clinical and Applied Sciences, Leeds Beckett University, Leeds, UK ${ }^{2}$ Coach House Sports Physiotherapy Clinic, Leeds, UK ${ }^{3}$ Division of Nursing, Midwifery and Social Work, School of Health Sciences, Faculty of Biology, Medicine and Health, University of Manchester, Manchester Academic Health Science Centre, Manchester, UK

${ }^{4}$ Research and Innovation Division, Central Manchester University Hospitals NHS Foundation Trust, Manchester Academic Health Science Centre; Jean McFarlane Building, Manchester, UK ${ }^{5}$ Centre for Pain Research, School of Clinical and Applied Sciences, Leeds Beckett University, Leeds, UK

\section{Correspondence to}

Gourav Banerjee,

g.banerjee@leedsbeckett.ac.uk

Accepted 11 February 2017

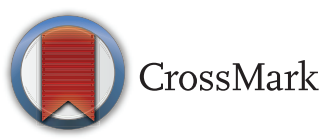

To cite: Banerjee $\mathrm{G}$, Rose $A$, Briggs $M$, et al. BMJ Case Rep Published online: [please include Day Month Year] doi:10.1136/ bcr-2016-216695

\section{SUMMARY}

We present the case of a woman who was an amateur athlete diagnosed with primary breast cancer, and 10 years later with terminal metastatic cancer. This case report was prepared posthumously in co-operation with her next of kin (husband). The patient first presented to a sports physiotherapist (AR) for her pain-management and to help maintain physical fitness so that she could continue with sports and an active lifestyle. The patient continued with physiotherapy for several months to enable her to be active. However, when her health deteriorated significantly due to advancing cancer, the treatment was modified and aimed at improving the patient's general well-being. The physiotherapist applied kinesiology tape over the patient's lower rib cage, diaphragm and abdomen in an attempt to manage pain, breathlessness and abdominal bloating. The patient reported alleviation of pain, breathlessness, abdominal discomfort and nausea, accompanied by improvements in eating, drinking, energy levels and physical function.

\section{BACKGROUND}

The global burden of cancer is significant and on the rise, ${ }^{1}$ and symptoms associated with cancer especially in advanced stages are burdensome. Symptom management is challenging yet critically important in the continuum of cancer care. ${ }^{2-5}$ The most common cancer-related symptoms include pain, fatigue, lack of energy, anorexia/weight loss, constipation, dyspnoea, nausea/vomiting, bloating and oedema, ${ }^{67}$ and they adversely affect physical, psychosocial and spiritual well-being and diminish quality of life. $^{289}$ The trade-off between symptom relief and adverse effects associated with pharmacotherapy may not be desirable for patients who are undergoing or have gone through intensive anticancer therapy. Non-pharmacological alternatives have become important adjuncts to pharmacotherapy.

Kinesiology taping is a non-pharmacological therapeutic technique that involves application of an elastic adhesive cotton-based tape on to the skin. Kinesiology taping was developed in 1970s by Kenzo Kase, a chiropractor for rehabilitation of musculoskeletal injuries, ${ }^{10}$ and the technique has gained popularity following its use by high-profile sports people in major sporting events including the Olympics. ${ }^{11}$ Nowadays physical and sports therapists, nurses, chiropractors and osteopaths use kinesiology taping to manage musculoskeletalrelated pain, cancer-related lymphoedema and stroke-related spasticity. ${ }^{12-14}$ Kinesiology tape can be purchased without prescription and is available in variety of shapes, sizes, colours and patterns. Kinesiology tape is made of water-resistant material and can be worn for 3-5 days while bathing and other activities. ${ }^{11} 15$ Kinesiology tape differs from conventional zinc-oxide adhesive tape as it can be stretched longitudinally up to $60 \%$ of its resting length and therefore can support soft tissues and joints without restricting movements. ${ }^{16}$

Manufacturers and advocates claim that the elastic property of kinesiology taping generates convolutions of the skin when in situ and that this improves blood and lymphatic microcirculation reducing pain and swelling. ${ }^{14} 16$ They claim that kinesiology taping causes exaggerated stretching and recoiling of the skin during movement and this stimulates low threshold cutaneous mechanoreceptors generating afferent impulses that inhibit nociceptive input that is, closing of the 'pain gate'. ${ }^{14} 16$ They also claim that kinesiology taping modulates myofascial tone resulting in rehabilitative benefits for musculoskeletal injuries. ${ }^{11} 16$ At present there is a paucity of scientific evidence to judge the merits of these claims.

There are at least 22 systematic reviews, some with meta-analysis, that have evaluated the efficacy of kinesiology taping, predominantly for musculoskeletal-related outcomes including pain. These 22 reviews include 95 studies with 3336 participants (table 1). Evidence from recent systematic reviews suggests that kinesiology taping is beneficial for non-acute musculoskeletal-related pain and disability when compared with minimal or no intervention controls. ${ }^{14}$ 17-19 A systematic review with meta-analysis on cancer-related lymphoedema found no significant difference between kinesiology taping and compression therapies for reducing lymph volume. ${ }^{20}$ Kinesiology taping was superior to compression for improving lymphoedemarelated symptoms; however, bandaging was associated with higher quality of life. It was also reported that kinesiology taping was associated with skin-related complications in up to $21 \%$ of patients. It was recommended that kinesiology taping be used with caution in patients where bandaging cannot be used.

Two systematic reviews, ${ }^{12} 13$ included a study by Tsai et $a l^{35}$ that evaluated the effect of kinesiology taping for cancer-related lymphoedema. Tsai et $a l,{ }^{35}$ found no differences between kinesiology taping and non-elasticated bandage for the reduction of moderate to severe breast cancer 
Table 1 Summary of systematic reviews and pooled analysis

\begin{tabular}{|c|c|c|}
\hline Not effective & Inconclusive/conflicting & Effective \\
\hline $\begin{array}{l}\text { Montalvo et al }{ }^{21} \\
{ }^{*} \mathrm{KT} \text { not superior to other treatments; has } \\
\text { limited potential for pain reduction which may } \\
\text { not be clinically meaningful }\end{array}$ & $\begin{array}{l}\text { Bassett et } \mathrm{al}^{25} \\
\mathrm{n}=3 \text {; MSK pain, muscle performance } \\
\text { * Insufficient evidence }\end{array}$ & $\begin{array}{l}\text { Artioli and Bertolini }{ }^{31} \\
n=10 ; \text { pain } \\
{ }^{*} \mathrm{KT} \text { similar/slightly superior to other physical therapies } \\
\text { for short-term pain reduction; KT can be considered as } \\
\text { an adjunct to other therapies }\end{array}$ \\
\hline $\begin{array}{l}\text { Parreira Pdo et al22 } \\
\quad \mathrm{n}=12 ; \text { MSK pain, disability, QoL, return to } \\
\text { work, global impression of recovery } \\
\text { *KT not superior to other treatments, sham } \\
\text { and placebo; effect sizes too small to have } \\
\text { clinical significance }\end{array}$ & $\begin{array}{l}\text { Mostafavifar et al }{ }^{11} \\
{ }^{*}=6 ; \text { Insufficient evidence; KT is a safe modality }\end{array}$ & $\begin{array}{l}\text { Hamneshin Behbahani et } a^{32} \\
\text { * } \mathrm{n}=11 \text {; lateral epicondylitis } \\
\text { strength, function and pain; strong evidence not } \\
\text { available }\end{array}$ \\
\hline $\begin{array}{l}\text { Csapo and Alegre }{ }^{23} \\
\mathrm{n}=19 ; \text { muscle strength in healthy } \\
\text { population } \\
{ }^{*} \mathrm{KT} \text { has no/negligible effects on muscle } \\
\text { strength }\end{array}$ & $\begin{array}{l}\text { Williams et al }{ }^{26} \\
{ }^{*} \text { small beneficial effect on strength, force sense error and active } \\
\text { ROM; insufficient evidence for pain, ankle proprioception and } \\
\text { muscle activity }\end{array}$ & $\begin{array}{l}\text { Ristow et als, }{ }^{33} \\
\text { and maxillofacial surgery } \\
{ }^{*} \text { KT significantly reduced swelling during the first } \\
2 \text { days postoperative; KT is simple, economical, without } \\
\text { systemic adverse reaction and improves patient's QoL. }\end{array}$ \\
\hline \multirow[t]{8}{*}{$\begin{array}{l}\text { Vanti et alt, } \\
{ }^{24} \\
\text { disability } \\
{ }^{*} \mathrm{KT} \text { has no immediate effect on reducing low } \\
\text { back pain and disability; small effect for neck } \\
\text { pain reduction which may not be clinically } \\
\text { relevant }\end{array}$} & $\begin{array}{l}\text { Morris et al }{ }^{12} \\
\mathrm{n}=6 \text {; MSK pain, ROM, disability, function } \\
\mathrm{n}=1 \text {; cancer-related lymphedema } \\
\mathrm{n}=1 \text {; stroke-related spasticity } \\
\text { reduction; limited/insufficient evidence KT not superior to other } \\
\text { treatments for lymphedema and other outcomes }\end{array}$ & $\begin{array}{l}\text { Lim and Tay }{ }^{14} \\
n=17 ; \text { MSK chronic pain and disability } \\
{ }^{*} \text { superior to minimal intervention but not to other } \\
\text { therapies for reducing pain and disability }\end{array}$ \\
\hline & $\begin{array}{l}\text { Kalron and Bar-Sela }{ }^{13} \\
\mathrm{n}=9 ; \text { MSK pain, muscle strength, ROM } \\
\mathrm{n}=2 ; \text { cancer-related lymphedema and oedema } \\
\mathrm{n}=1 \text {; stroke-related spasticity } \\
\text { 'moderate evidence for short-term pain reduction but not for } \\
\text { long-term; no/inconclusive evidence for muscle strength, ROM, } \\
\text { oedema/lymphedema and spasticity }\end{array}$ & $\begin{array}{l}\text { Chang et alt, }{ }^{17} \\
n=11[N E T(n=6)+K T(n=5)] ; \text { PFPS } \\
{ }^{*} \text { can improve pain, muscle activity, motor function and } \\
\text { QoL but cannot change patellar alignment }\end{array}$ \\
\hline & $\begin{array}{l}\text { Méndez-Rebolledo et } a^{27} \\
{ }^{2} \text { Insufficient evidence of quality }\end{array}$ & $\begin{array}{l}\text { Wilson and Bialocerkowski }{ }^{18} \\
{ }^{*} \text { positive effects on proprioception, muscle endurance } \\
\text { and activity performance and so useful for preventing/ } \\
\text { managing lateral ankle injuries }\end{array}$ \\
\hline & $\begin{array}{l}\text { Desjardins-Charbonneau et alt, }{ }^{19} \\
n=10[N E T(n=4)+K T(n=6)] ; \text { SIS/RotCuffTend } \\
{ }^{*} \mathrm{KT} \text { significantly improved pain-free ROM however insufficient } \\
\text { evidence to judge efficacy as standalone/adjunct }\end{array}$ & $\begin{array}{l}\text { Dong et al } \neq \text {, } \\
\text { RotCuffTend } \\
\text { *exercise and other therapies like KT are ideal } \\
\text { treatments in early stage SIS/ RotCuffTend }\end{array}$ \\
\hline & $\begin{array}{l}\text { Beatriz and Rafael, }{ }^{28} \\
\text { * } n=12 ; \text { PFPS } \\
\text { can be used alongside other therapies }\end{array}$ & \\
\hline & $\begin{array}{l}\text { Grampurohit et alt, } \\
{ }^{29} \\
\text { * } n=15 \text { [NET }(n=13)+K T(n=2)] \text {; post-stroke outcomes } \\
\text { function }\end{array}$ & \\
\hline & $\begin{array}{l}\text { Gatt et } a^{20} \\
{ }^{*}=6 ; \text { cancer-related lymphedema } \\
\text { *No significant difference between KT and compression } \\
\text { bandaging/hosiery; KT should be used with caution when } \\
\text { bandaging cannot be used }\end{array}$ & \\
\hline & $\begin{array}{l}\text { Nelson } 2016^{30} \\
\text { * } \mathrm{n}=5 \text {; chronic low back pain } \\
\text { (moderate evidence that KT not more effective than conventional } \\
\text { PT/exercise for reducing pain and disability as standalone/ } \\
\text { adjunct; insufficient/limited evidence that KT superior to sham } \\
\text { for reducing pain, disability and ROM) }\end{array}$ & \\
\hline
\end{tabular}

(Author, Year; $\mathrm{n}=$ number of included studies; Outcome Measures).

${ }^{*}$ Additional comments.

tStudies evaluating effectiveness of taping in general which includes kinesiology (elastic) taping and non-elastic taping.

¥Studies evaluating effectiveness of interventions for shoulder impingement syndrome that include kinesiology taping, pharmacotherapy and surgery.

$\S$ Study is a pooled analysis.

KT, kinesiology taping; MSK, musculoskeletal; NET, non-elastic taping; PFPS, patellofemoral pain syndrome; PT, physical therapy; QoL, quality of life; ROM, range of motion; SIS/ RotCuffTend, shoulder impingement syndrome/rotator cuff tendinopathy. 
related-lymphoedema. In addition, kinesiology taping was found more comfortable and convenient to apply than bandage, and could be worn for longer duration of time. Previously, we have reported the findings of a literature review of studies that have evaluated the use of kinesiology taping for cancer. ${ }^{36}$ Five of seven studies with a comparison group found that kinesiology taping may be a useful addition to decongestive therapy for managing breast cancer-related stage 1 or 2 lymphoedema, including reduction in pain and improvement in upper limb range of motion (ROM). ${ }^{35}{ }^{37-40}$ Two studies on the other hand found that kinesiology taping was not superior to the multilayered bandaging when combined with manual lymphatic drainage and pneumatic compression for reducing breast cancerrelated stage 2 or 3 lymphoedema. ${ }^{41}{ }^{42}$ Nevertheless, kinesiology taping was associated with improvements in limb volume reduction and upper limb $\mathrm{ROM},{ }^{42}$ which could be of clinical relevance in patients that are ill-suited to the multilayered bandaging. Overall, it seems kinesiology taping may not be superior to existing therapies for lymphoedema management but may be useful in select patients with early stage I and II lymphoedema. Thus, expert groups support the use of kinesiology taping as an adjunct for managing lymphoedema. ${ }^{43}{ }^{44}$ Since the publication of the most recent systematic review, Imperatori et al, ${ }^{45}$ have published a randomised controlled clinical trial that found the addition of kinesiology taping to standard postoperative analgesia produced greater relief of immediate and long-term (30 days postoperative) lobectomy-associated chest pain compared with the addition of dressing tape. Kinesiology taping was not associated with any adverse effects and it was concluded that kinesiology taping was a safe and effective auxiliary technique for the management of postoperative chest pain after lung lobectomy. This provides further evidence that kinesiology taping may have a role as an adjunct in the management of pain and other symptoms in the continuum of cancer care. ${ }^{46}$

In this case report, we describe the use of kinesiology taping to manage pain, breathlessness and abdominal discomfort for a woman diagnosed with secondary breast cancer.

\section{CASE PRESENTATION}

The following is a case presentation based on clinical notes and diary entries of a patient who was treated by a physiotherapist (AR).

In 2006, an amateur woman athlete in her early 40s selfreferred to a specialist sports physiotherapist (AR) at a private clinic to seek relief from hip pain and for help preparing for a 3000 miles cycling challenge. The patient had been diagnosed with primary breast cancer in 1990, for which she underwent lumpectomy and 3 years later mastectomy, radiotherapy and chemotherapy. In 2000, the patient received a diagnosis of terminal breast cancer with malignant metastatic tumours of the lungs, liver and bone.

In 2007, the patient presented unwell to AR following completion of the cycling challenge and chemotherapy. The patient reported 'low' levels of energy, 'severe' nausea, 'moderate to severe' breathlessness and 'severe' abdominal bloating. She also reported anterior rib, mid thoracic, sacral and left-sided pelvic pain, night sweats that soaked the bed and reduced muscle strength that had negatively affected her daily living activities. She rated her mood as 'low'. The patient was scheduled for further sessions of chemotherapy and vertebroplasty to treat vertebral compression fractures the lower cervical and midthoracic spinal region that had resulted from the metastases.
On palpation the patient's right lower lobe of the liver felt enlarged, solid, tender and relatively immobile. The liver was pressing into the abdominal area and affecting the diaphragmatic excursion. The patient's rib expansion was poor and relatively immobile in the midinhalation position with the work of breathing mainly through the upper ribs. The paraspinal muscles were in spasm. The patient reported that nausea was making it very difficult to eat and drink, and when she was able to eat, she felt very bloated afterwards. The patient sipped protein drinks to maintain strength so that she could partake in family and social gatherings. The patient's pain was being managed by fentanyl patches, oramorph (for breakthrough pain), paracetamol and meloxicam.

In this first physiotherapy consultation, the patient was too unwell to be given 'hands-on' physiotherapy treatment. Therefore, kinesiology taping was applied in an attempt to mitigate pain and breathlessness and abdominal discomfort associated with swelling/oedema. It was believed that kinesiology taping may help to support the abdomen and thorax and aid respiratory movements. The elastic nature of kinesiology tape was seen as an advantage over other types of tape which can restrict movement. The patient was very willing to try kinesiology taping. AR conducted a telephone consultation with a physiotherapy colleague who had experience of treating similar patients with kinesiology taping to determine an appropriate kinesiology taping technique.

\section{TREATMENT}

The kinesiology tape was cut to create a series of thin strips 'fans' and applied over the patient's rib cage, diaphragm and abdomen to support drainage of accumulated fluids (figures 1-3). Kinesiology tape was applied when the patient held the inspiration phase of the breathing cycle, with the tape stretched to $\sim 10-20 \%$ of its original length. The 'fans' of the kinesiology tape were directed towards the base of axilla and anchored in the vicinity of axillary lymph nodes.

The patient was advised to continue as normal with pain medication. It was agreed that the patient would return to clinic for follow-up in 5 days after which she would be assessed at home at $\sim 10$ day intervals. The patient was advised to leave kinesiology tape in situ for 7 to 10 days or unless she wished to remove it because of the tape becoming uncomfortable to continue wearing, any skin reactions or the tape started to become slack and detach from the skin of its own accord. The patient had been instructed to remove the tape if there were any adverse skin effects like itching, rash or discomfort.

\section{OUTCOME AND FOLLOW-UP}

The patient presented to clinic for her second physiotherapy consultation 5 days after the initial consultation. The patient was very cheerful and reported that she was feeling markedly better with mood rated as 'moderate to high'. The patient was breathing easier and she rated reductions in breathless 'moderate to mild', abdominal bloating 'mild' and nausea 'mild'. The patient reported that she was better able to eat and drink and this made her feel more energised. She rated her energy levels as 'high'. Pain in the anterior ribcage area where the kinesiology tape had been applied was reduced. Pain in the sacral-pelvic region was unchanged and controlled by analgesic medication. The old kinesiology tape was removed from the skin and the patient treated with gentle soft tissue therapy of the lower ribs, upper right quadrant of the abdomen overlying the liver and the posterior abdomen in the region of the upper lumbar and lower thoracic vertebrae overlying the kidneys. This involved applying 


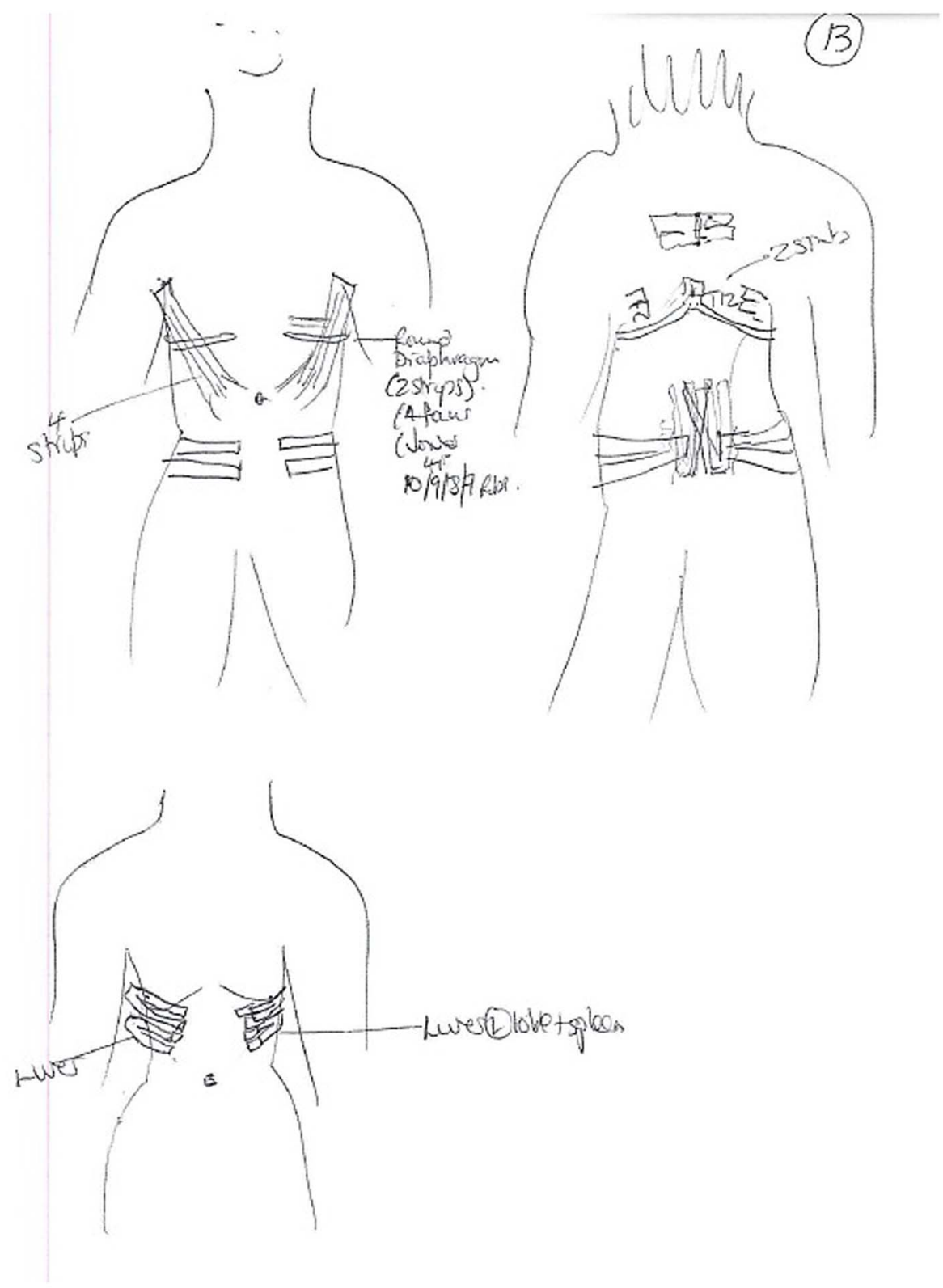

Figure 1 Sketches of the location of kinesiology taping from the physiotherapy case notes.

gentle pressure to, and stretching and massage of, underlying structures using osteopathic techniques. The aim of soft tissue therapy was to relieve pain and discomfort and improve mobility and functional activities including breathing. After this, the kinesiology tape was applied using the same technique as the first consultation.

The third consultation was a home-visit undertaken by a different physiotherapist 15 days after the second consultation. The patient had removed the tape after 8 days and reported that improvement in symptoms had been maintained between the treatment sessions. New kinesiology tape was applied using the same technique as at the first consultation.

The fourth physiotherapy consultation was a home-visit that took place 17 days after the third consultation (ie, 36 days after the initial physiotherapy consultation). The patient appeared very fatigued which was attributed to recent chemotherapy. The patient asserted that kinesiology taping had made a 'huge difference' reporting that she had experienced reductions in rib pain, nausea, bloating and breathless. On assessment, there was restricted mobility of the rib, liver, diaphragm and there was restricted posterior-anterior mobility of the quadratus lumborum. The patient was treated as previously with gentle soft tissue therapy and was taught breathing exercises. Old kinesiology tape was replaced with new kinesiology tape using the same technique as at the first physiotherapy consultation.

The patient chose not to receive further chemotherapy after the fourth physiotherapy consultation. The patient's status remained stable over the next month during which three homeconsultations took place that is, 48, 62 and 69 days respectively after the initial physiotherapy consultation. At each visit gentle soft tissue therapy and kinesiology taping was administered. The patient continued to report benefits from kinesiology taping and symptoms remained stable with breathlessness rated as 'moderate to mild', nausea as 'mild' and abdominal bloating as 'mild'. Energy and mood was rated as 'moderate to high' and pain in the anterior ribcage area and sacral-pelvic region unchanged.

During the next 2 months the patient's health deteriorated more noticeably due to the advancing cancer disease. The 


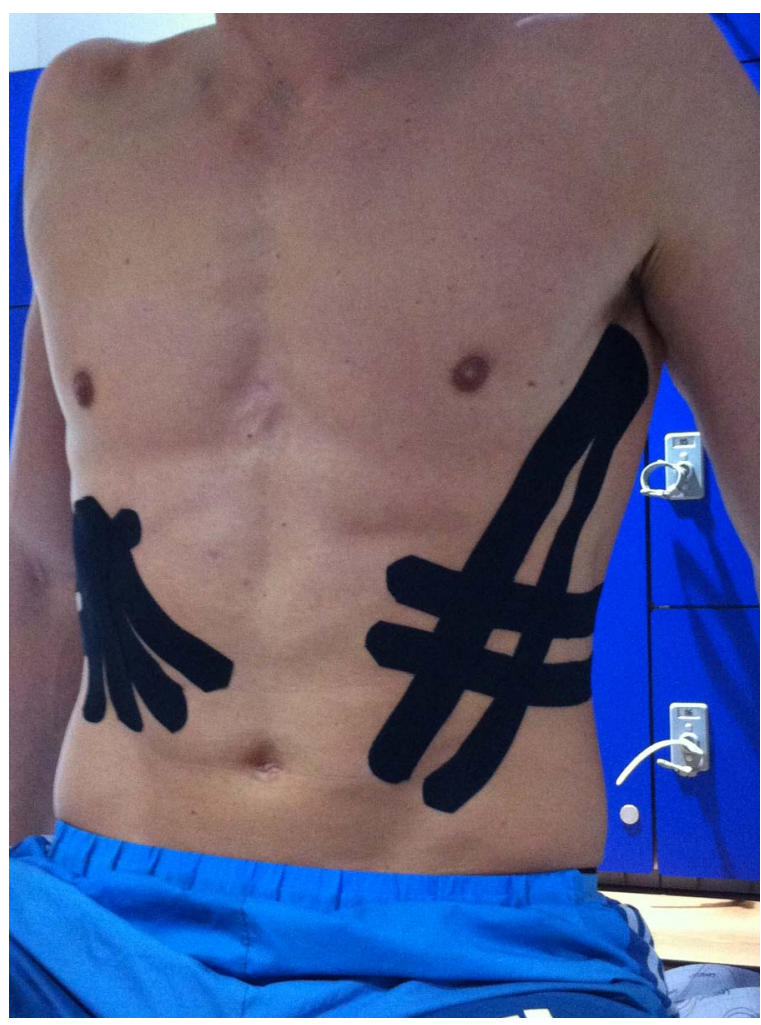

Figure 2 Kinesiology taping technique used to encourage lymphatic drainage. The 'fans' of the kinesiology tape, which is applied with $\sim 10-20 \%$ stretch is alleged to direct the flow of lymph towards the base which is placed near the axillary lymph nodes. The person in the figure is a healthy individual rather than the actual patient.

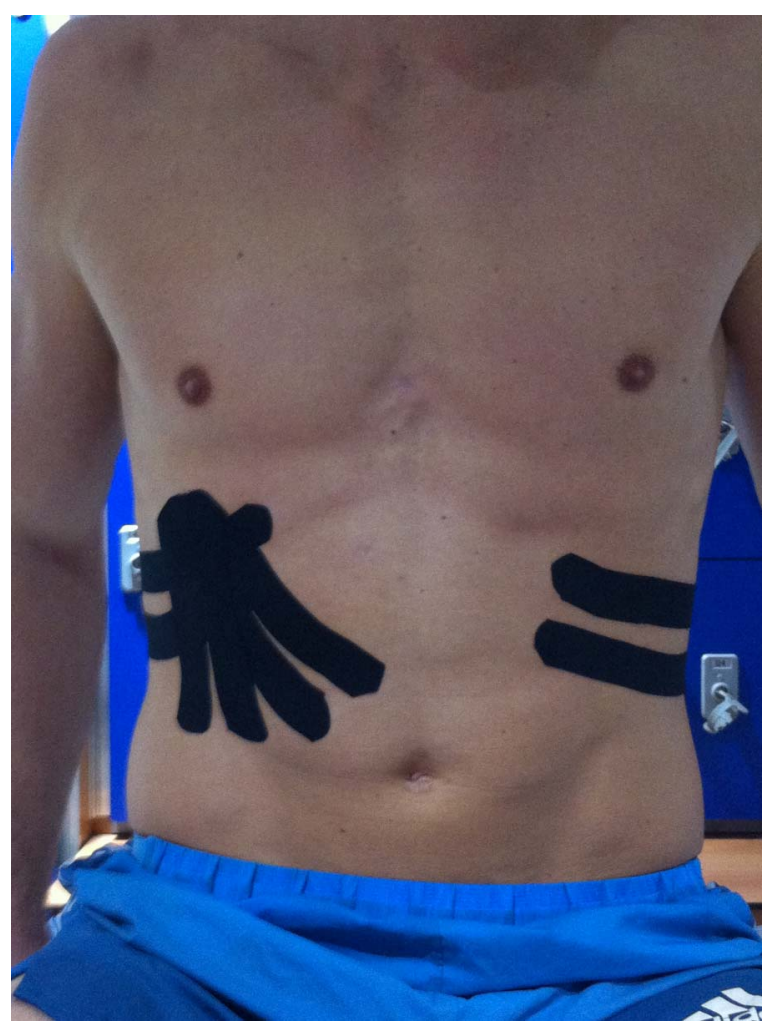

Figure 3 Kinesiology taping technique used to reduce swelling in the lower region of the liver which had been metastasised. Kinesiology tape was applied with $\sim 10-20 \%$ stretch. The person in the figure is a healthy individual rather than the actual patient. patient received five home consultations during this time. Kinesiology taping was administered during each consultation in conjunction with extremely gentle hands-on physiotherapy until the final two treatments where only kinesiology taping was deemed appropriate. Throughout the course of kinesiology taping treatment no adverse effect was reported by the patient. The patient was extremely unwell at the last home consultation (134 days after the first consultation) and she did not wish further physiotherapy. At this point the patient realised how ill she was and that she was nearing the end of her life.

\section{DISCUSSION}

There are a few case reports and case series that have investigated the use of kinesiology taping in cancer. Those that exist have found kinesiology taping to be associated with improvements in cancer-related lymphoedema, ${ }^{47-53}$ pain, ${ }^{48}$ ROM of the upper limb, ${ }^{47}$ muscle tightness/heaviness/discomfort, ${ }^{47} \quad 48 \quad 50$ tissue texture ${ }^{49} 52$ and upper limb function and disability. ${ }^{50} 54$ Other noticeable findings in the literature were that kinesiology taping could be an alternate choice for patients who are unsuitable for decongestive lymphoedema therapy, ${ }^{48} 51$ and could be used for 'challenging areas' of the body, although there was concern about hygiene associated with the tape in situ. ${ }^{49}$

A clinical study $(n=24),{ }^{54}$ found that kinesiology taping was not associated with reductions in lymph volume in patients with breast cancer; however, it was reported by the patients that they felt more confident when performing daily activities and this resulted in improvements of upper limb functionality. A patient in that study reported peeling of the skin and redness. In a pretest and post-test study $(n=14),{ }^{55}$ no differences were observed between kinesiology taping and compression sleeves for outcome measures that included quality of life scores, symptom intensity, arm volume and satisfaction of treatment in patients with breast cancer. It was concluded that kinesiology taping may be a possible alternative to compression sleeve for managing upper limb lymphoedema.

Kinesiology taping has also been found to be useful for managing pain in cancer conditions. Two case reports, ${ }^{56} 57$ found that kinesiology taping added to soft tissue therapies and exercise reduced pain, improved joint ROM, physical function and quality of life in four elderly patients with secondary breast cancer $(n=2)$, advanced lung cancer $(n=1)$, and multiple myeloma $(n=1)$. It was reported by all patients that they were satisfied with kinesiology taping treatment. In a case of a middle-aged woman who underwent partial glossectomy and neck dissection following tongue cancer, ${ }^{58}$ kinesiology taping added to manual therapy, exercise and patient education reduced cervical spine region pain and improved shoulder ROM, muscle strength and function.

In a recent case report by Banerjee et al $(\mathrm{n}=1),{ }^{59}$ it was found that the addition of kinesiology taping to soft tissue therapy significantly reduced musculoskeletal pain (by 50\%) and 'tearing' and 'searing' -like sensations (by $\sim 85 \%$ ) compared with pretreatment in a patient with secondary breast cancer. The patient felt greater control and stability over her left shoulder region where the kinesiology tape was applied which resulted in better functioning of the upper limb. The patient reported no adverse effects.

Given the evidence that is available to date, we speculate that kinesiology taping could be useful in cancer conditions for mitigating pain and symptoms secondary to oedematous conditions (eg, pleural effusion and ascites) such as breathlessness, abdominal bloating, nausea and lack of energy. Kinesiology taping could also be useful in instances where support to the soft 
tissues or biomechanical alignment is required-for example, rotator cuff tendinopathy, ${ }^{19}$ and patellofemoral pain syndrome. ${ }^{17} 28$

The patient in our case reported significant improvements in abdominal-related symptoms, breathlessness and pain after the use of kinesiology taping, which contributed to better physical functioning that improved quality of life. However, a causeeffect relationship cannot be established and there is evidence that other types of therapeutic tape have been associated with pain relief in patellofemoral pain syndrome, ${ }^{60-62}$ so any putative effect may not be specific to kinesiology taping per se. Nevertheless, there is better skin tolerance to kinesiology taping than other therapeutic tapes. ${ }^{18} 28$

In conclusion, kinesiology taping could be useful as an adjunct in the continuum of cancer care. It offers important advantages that include low-cost and over-the-counter availability. Kinesiology taping can be administered by carers or by patients themselves as this technique is relatively easy to learn. This empowers patients to self-manage their symptoms. Precautions to using kinesiology taping include allergy to the tape, open wounds, frail skin, dermatological (eg, eczema) and vascular diseases (deep vein thrombosis). ${ }^{46}$ Some manufacturers have raised fear of spreading cancer because of improvements in lymphatic and blood circulation due to kinesiology taping in patients with active cancer; further research is warranted. We hope that this case will generate interest among oncology and palliative/supportive care health professionals and researchers to evaluate this therapy further.

Patient's perspective

- "My wife had taken part in a mammoth endurance challenge of 10 weeks between June and September 2006. At the time, she had cancer in her liver and many bones. Upon her return to home, with a big loss in body weight and untreated disease, she was in extreme discomfort.

- From October to February, her health declined steadily and oncology treatment was not having a great effect. Swelling of the liver and the extensive other bone disease was making normal everyday jobs difficult and painful. My wife was not at the time in very good physical and top endurance condition.

- After the first treatment of kinesiology taping in March 2007, there was an instantaneous improvement in physical condition. The pain and discomfort, which affected her daily life, had vastly reduced. The improvement was consistent throughout the time of the treatment. Regular replacement of the kinesiology tape was needed as the tape seemed to not be as effective- the longer the tape was on, the more slack it became.

- Throughout the period from March to July, my wife's health deteriorated. My wife had a high tolerance of pain and never took the amount of pain relief that was recommended due to her desire to be fully bright and alert. In this time, the liver and stomach continued to swell as if she was in the early months of pregnancy.

- Without the kinesiology taping I am convinced her deterioration would have progressed quicker. My wife was able to be mobile, continue to do all household chores, be a mum and take on moderate physical exercise. She ran a $1.5 \mathrm{~km}$ run with our son in mid-July 2007 at a reasonable pace.
- By early August 2007, it was decided there would be no treatment and she was admitted to a hospice for pain relief. She had been using very little pain relieving medication at this point. The kinesiology tape was removed at this point as well. Doctor's advice was she would be in the hospice for a short period and then be able to come home for several months. The cancer had other ideas and she died 3 weeks after.

- The major benefit of the kinesiology taping was improvement in quality of life and being physically comfortable. As soon as the kinesiology tape was applied the improvement was immediate, could this have been psychological-not a chance! Most people who knew my wife would agree that she had enormous mental strength and pain tolerance. The tape gave her back her freedom of movement and for several months her life. This unexpected improvement had a great impact on not just the patient but also all those close to her."

\section{Learning points}

- Kinesiology taping is an easy-to-apply therapeutic technique that is used by healthcare professionals including physical therapists and nurses to manage lymphoedema and associated outcomes including pain.

- Kinesiology tape can be bought over-the-counter and is relatively easy to apply by a carer or patient. This infers less reliance on healthcare professionals and use of resources.

- Kinesiology taping could be useful in select patients with cancer as an adjunct for managing pain and symptoms secondary to oedema and this could improve physical function and quality of life. The most serious adverse effect appears to be mild-to-moderate irritation of the skin, for example, red, tender and peeling skin on removal of the tape.

- The mechanism of action is uncertain, although we suspect that the tape may provide support to body structures (eg, splinting) without restricting movement and this alleviates abdominal discomfort and breathlessness.

- The subjective improvement in symptoms in this case suggests that further research using validated instruments and objective measures might be useful to assess the potential benefit of kinesiology taping for others.

Acknowledgements This project was funded by a PhD student bursary from the Jane Tomlinson Appeal. No outside contribution was requested or received during the preparation of this article.

Contributors MIJ, MB and GB conceived the case report. AR executed the treatment at a clinic; other necessary information was provided by the patient's next of kin. AR undertook physiotherapy-related assessment and treatment responsibilities of this case. All authors contributed to the writing of the manuscript and approved the final manuscript.

Funding The Jane Tomlinson Appeal.

Competing interests None declared.

Patient consent Obtained.

Provenance and peer review Not commissioned; externally peer reviewed.

Open Access This is an Open Access article distributed in accordance with the Creative Commons Attribution Non Commercial (CC BY-NC 4.0) license, which permits others to distribute, remix, adapt, build upon this work non-commercially, and license their derivative works on different terms, provided the original work is properly cited and the use is non-commercial. See: http://creativecommons.org/ licenses/by-nc/4.0/ 


\section{REFERENCES}

1 Jemal A, Bray F, Center MM, et al. Global cancer statistics. CA Cancer J Clin 2011:61:69-90.

2 Fan G, Filipczak L, Chow E. Symptom clusters in cancer patients: a review of the literature. Curr Oncol 2007;14:173.

3 Cleeland CS, Sloan JA, Group AO. Assessing the symptoms of cancer using patient-reported outcomes (ASCPRO): searching for standards. J Pain Symptom Manage 2010;39:1077-85.

4 Cleeland CS, Zhao F, Chang VT, et al. The symptom burden of cancer: evidence for a core set of cancer-related and treatment-related symptoms from the Eastern Cooperative Oncology Group Symptom Outcomes and Practice Patterns study. Cancer 2013:119:4333-40.

5 Steel JL, Geller DA, Kim KH, et al. Web-based collaborative care intervention to manage cancer-related symptoms in the palliative care setting. Cancer 2016;122:1270-82.

6 Walsh D, Donnelly S, Rybicki L. The symptoms of advanced cancer: relationship to age, gender, and performance status in 1,000 patients. Support Care Cancer 2000;8:175-9.

7 Teunissen SC, Wesker W, Kruitwagen C, et al. Symptom prevalence in patients with incurable cancer: a systematic review. J Pain Symptom Manage 2007;34:94-104.

8 Raphael J, Ahmedzai S, Hester J, et al. Cancer pain: part 1: pathophysiology; oncological, pharmacological, and psychological treatments: a perspective from the British Pain Society endorsed by the UK Association of Palliative Medicine and the Royal College of General Practitioners. Pain Med 2010;11:742-64.

9 Kroenke K, Zhong X, Theobald D, et al. Somatic symptoms in patients with cancer experiencing pain or depression: prevalence, disability, and healthcare use. Arch Intern Med 2010;170:1686-94.

10 Kinesio $®$ UK. Kinesio $®$ UK: A Brief History of Kinesio Tex Taping $®$. Secondary Kinesio ${ }^{\circledR}$ UK: A Brief History of Kinesio Tex Taping®. 2016. http://www. kinesiotaping.co.uk/history.jsp

11 Mostafavifar M, Wertz J, Borchers J. A systematic review of the effectiveness of kinesio taping for musculoskeletal injury. Phys Sportsmed 2012;40:33-40.

12 Morris $D$, Jones $D$, Ryan $H$, et al. The clinical effects of Kinesio $®$ Tex taping: a systematic review. Physiother Theory Pract 2013;29:259-70.

13 Kalron A, Bar-Sela S. A systematic review of the effectiveness of Kinesio Tapingfact or fashion? Eur J Phys Rehabil Med 2013;49:699-709.

14 Lim ECW, Tay MGX. Kinesio taping in musculoskeletal pain and disability that lasts for more than 4 weeks: is it time to peel off the tape and throw it out with the sweat? A systematic review with meta-analysis focused on pain and also methods of tape application. Br J Sports Med 2015;49:1558-66.

15 Kinesio®UK. Frequently Asked Questions about Kinesio Taping®. Secondary Frequently Asked Questions about Kinesio Taping®. 2016. http://kinesiotaping.co. uk/faq.jsp

16 Kase K, Wallis J, Kase T, et al. Clinical therapeutic applications of the Kinesio taping method. 3rd edn. Kinesio, USA, LLC, 2013.

17 Chang WD, Chen FC, Lee CL, et al. Effects of Kinesio Taping versus McConnell Taping for patellofemoral pain syndrome: a systematic review and meta-analysis. Evid Based Complement Altern Med 2015;2015:471208.

18 Wilson B, Bialocerkowski A. The effects of Kinesio tape applied to the lateral aspect of the ankle: relevance to ankle sprains-a systematic review. PLOS ONE 2015;10: e0124214

19 Desjardins-Charbonneau A, Roy JS, Dionne CE, et al. The efficacy of taping for rotator cuff tendinopathy: a systematic review and meta-analysis. Int I Sports Phys Ther 2015:10:420-33.

20 Gatt M, Willis S, Leuschner S. A meta-analysis of the effectiveness and safety of kinesiology taping in the management of cancer-related lymphoedema. Eur J Cancer Care (Engl) 2016

21 Montalvo AM, Cara EL, Myer GD. Effect of kinesiology taping on pain in individuals with musculoskeletal injuries: systematic review and meta-analysis. Phys Sportsmed 2014;42:48-57.

22 Parreira Pdo C, Costa Lda C, Hespanhol LC Jr, et al. Current evidence does not support the use of Kinesio Taping in clinical practice: a systematic review. J Physiother 2014;60:31-9.

23 Csapo R, Alegre LM. Effects of Kinesio $®$ taping on skeletal muscle strength-a meta-analysis of current evidence. J Sci Med Sport 2015:18:450-6.

24 Vanti C, Bertozzi L, Gardenghi l, et al. Effect of taping on spinal pain and disability: systematic review and meta-analysis of randomized trials. Phys Ther 2015:95:493-506.

25 Bassett KT, Lingman SA, Ellis RF. The use and treatment of kinaesthetic taping for musculoskeletal conditions: a systematic review. N Z J Physiother 2010;38:56-62.

26 Williams S, Whatman C, Hume PA, et al. Kinesio taping in treatment and prevention of sports injuries. Sports Med 2012;42:153-64

27 Méndez-Rebolledo G, Gatica-Rojas V, Cuevas-Contreras D, et al. Efectos del kinesio tape en la rehabilitación de pacientes con síndrome de dolor patelofemoral: una revisión sistemática. Fisioterapia 2014;36:280-7.

28 Beatriz LA, Rafael M-M. Kinesio taping and patellofemoral pain syndrome: a systematic review. Cent Eur J Sport Sci Med 2015;9:47-54.
29 Grampurohit N, Pradhan S, Kartin D. Efficacy of adhesive taping as an adjunt to physical rehabilitation to influence outcomes post-stroke: a systematic review. Top Stroke Rehabil 2015;22:72-82

30 Nelson NL. Kinesio taping for chronic low back pain: a systematic review. J Bodyw Mov Ther 2016;20:672-81.

31 Artioli DP, Bertolini GRF. Kinesio taping: application and results on pain: systematic review. Fisioterapia e Pesquisa 2014;21:94-9.

32 Hamneshin Behbahani S, Arab AM, Nejad L. Systematic review: effects of using Kinesio Tape on treatment of lateral epicondylitis. Physical Treatments-Specific Physical Therapy Journal 2014;4:115-22.

33 Ristow O, Pautke C, Kehl V, et al. Kinesiologic taping reduces morbidity after oral and maxillofacial surgery: a pooled analysis. Physiother Theory Pract 2014:30:390-8.

34 Dong W, Goost $H$, Lin XB, et al. Treatments for shoulder impingement syndrome: a PRISMA systematic review and network meta-analysis. Medicine (Baltim) 2015;94: e510.

35 Tsai HJ, Hung HC, Yang JL, et al. Could Kinesio tape replace the bandage in decongestive lymphatic therapy for breast-cancer-related lymphedema? A pilot study. Supportive Care in Cancer 2009;17:1353-60.

36 Banerjee $\mathrm{G}$, Rose $\mathrm{A}$, Briggs $\mathrm{M}$, et al. Kinesiology taping as a novel adjunct in oncology and palliative care? British Psychosocial Oncology Society 2016 Annual Conference. Madingley Hall, University of Cambridge, United Kingdom: Wiley Online Library, 2016:22.

37 Bosman J, Piller N. Lymph taping and seroma formation post breast cancer. J Lymphoedema 2010;5:12-21.

38 Pop TB, Karczmarek-Borowska B, Tymczak M, et al. Original paper the influence of Kinesiology Taping on the reduction of lymphoedema among women after mastectomy-preliminary study. Contemp Oncol (Pozn) 2014;18:124-9.

39 Pekyavaş NÖ, Tunay VB, Akbayrak T, et al. Complex decongestive therapy and taping for patients with postmastectomy lymphedema: a randomized controlled study. Eur J Oncol Nurs 2014;18:585-90.

40 Malicka I, Rosseger A, Hanuszkiewicz J, et al. Kinesiology Taping reduces lymphedema of the upper extremity in women after breast cancer treatment: a pilot study. Prz Menopauzalny 2014;13:221-6.

41 Smykla A, Walewicz K, Trybulski R, et al. Effect of Kinesiology Taping on breast cancer-related lymphedema: a randomized single-blind controlled pilot study. BioMed Res Int 2013;2013:767106.

42 Taradaj J, Halski T, Rosinczuk J, et al. The influence of Kinesiology Taping on the volume of lymphoedema and manual dexterity of the upper limb in women after breast cancer treatment. Eur J Cancer Care (Engl) 2016;25:647-60.

43 International Lymphoedema Framework and Canadian Lymphedema Framework. The management of lymphoedema in advanced cancer and oedema at the end of life. Secondary The management of lymphoedema in advanced cancer and oedema at the end of life. 2010. http://www.soffed.co.uk/lymphorg/wp-content/uploads/ 2016/03/Palliative-Document.pdf

44 The British Lymphology Society. BLS lymphoedema awareness week: the five guide. Secondary BLS lymphoedema awareness week: the five guide. 2016. http:/ lipedemaproject.org/wp-content/uploads/2016/02/BLS_The-Detailed-OnlineFive-Guide.pdf

45 Imperatori A, Grande A, Castiglioni M, et al. Chest pain control with kinesiology taping after lobectomy for lung cancer: initial results of a randomized placebo-controlled study. Interact Cardiovasc Thorac Surg 2016;23:223-30.

46 Banerjee $G$, Rose $A$, Briggs $M$, et al. Kinesiology taping as an adjunct for the management of symptoms in the continuum of cancer care? Support Care Cancer 2016:24:3283-4.

47 Lipińska A, Śliwiński Z, Kiebzak W, et al. The influence of Kinesiotaping applications on lymphoedema of an upper limb in woman after mastectomy. Fizjo Pol 2007;7:258-69.

48 Pyszora A, Krajnik M. Is Kinesio Taping useful for advanced cancer lymphoedema treatment? A case report. Adv Palliat Med 2010;9:141-4.

49 Finnerty S, Thomason S, Woods M. Audit of the use of kinesiology tape for breast oedema. J Lymphoedema 2010;5:38-44.

50 Kaya E, Kaplan C, Dandin Ö. Kinesiotaping for breast cancer related lymphedema. J Breast Health 2012;8:166-8.

51 Chou YH, Li SH, Liao SF, et al. Case report: manual lymphatic drainage and kinesio taping in the secondary malignant breast cancer-related lymphedema in an arm with arteriovenous (AV) fistula for hemodialysis. Am J Hosp Palliat Care 2013:30:503-6.

52 Taradaj J, Halski T, Zdunczyk M, et al. Evaluation of the effectiveness of kinesio taping application in a patient with secondary lymphedema in breast cancer: a case report. Przeglad Menopauzalny 2014;18:73-7.

53 Navarro-Brazález B, Sánchez-Sánchez B. El vendaje en el tratamiento fisioterapéutico del linfedema secundario a cancer de mama: una serie de casos. Fisioterapia 2014;36:49-53.

54 Martins Jde C, Aguiar SS, Fabro EAN, et al. Safety and tolerability of Kinesio ${ }^{\circledR}$ Taping in patients with arm lymphedema: medical device clinical study. Support Care Cancer 2016;24:1119-24. 


\section{Novel treatment (new drug/intervention; established drug/procedure in new situation)}

55 Hubert $\mathrm{P}$, Gelais SS, Harris $\mathrm{K}$, et al. The effects of SpiderTech ${ }^{\mathrm{TM}}$ kinesiology tape on the management of lymphedema in patients that are status post breast cancer treatment. Rehabil Oncol 2013;31:47.

56 Pyszora A, Graczyk M, Krajnik M. What is the role of a physiotherapist in palliative care? Cases report. Adv Palliat Med 2009;8:31-4.

57 Pyszora A, Wójcik A, Krajnik M. Are soft tissue therapies and Kinesio Taping usefu for symptom management in palliative care? Three case reports. Adv Palliat Med 2010;9:87-92.

58 Courtney-Koro S. Rehabilitation following partial glossectomy and neck dissection for tongue cancer. Rehabil Oncol 2004;22:15-20.
59 Banerjee $\mathrm{G}$, Rebanks J, Briggs $\mathrm{M}$, et al. Kinesiology taping as an adjunct for pain management in cancer? BMJ Case Rep 2016;2016:bcr2016216439.

60 Aminaka N, Gribble PA. A systematic review of the effects of therapeutic taping on patellofemoral pain syndrome. J Athl Train 2005;40:341-51.

61 Warden SJ, Hinman RS, Watson MA Jr, et al. Patellar taping and bracing for the treatment of chronic knee pain: a systematic review and meta-analysis. Arthritis Rheum 2008;59:73-83.

62 Barton C, Balachandar V, Lack S, et al. Patellar taping for patellofemoral pain: a systematic review and meta-analysis to evaluate clinical outcomes and biomechanical mechanisms. Br J Sports Med 2014;48:417-24.

Copyright 2017 BMJ Publishing Group. All rights reserved. For permission to reuse any of this content visit http://group.bmj.com/group/rights-licensing/permissions.

BMJ Case Report Fellows may re-use this article for personal use and teaching without any further permission.

Become a Fellow of BMJ Case Reports today and you can:

- Submit as many cases as you like

- Enjoy fast sympathetic peer review and rapid publication of accepted articles

- Access all the published articles

- Re-use any of the published material for personal use and teaching without further permission

For information on Institutional Fellowships contact consortiasales@bmjgroup.com

Visit casereports.bmj.com for more articles like this and to become a Fellow 